\title{
Perspectives on the Elimination of Cancer Cells Using Rhodochrosite Crystal Through Synchrotron Radiation, and Absorption the Tumoral and Non- Tumoral Tissues
} \author{
Gobato $^{5}$ \\ ${ }^{1}$ Laboratory of Biophysics and Molecular Modeling Genesis, State Secretariat of Education of Parana, Brazil. \\ ${ }^{2}$ Department of Chemistry, Kufa University, Iraq \\ ${ }^{3}$ Department of Chemistry, California South University, USA \\ ${ }^{4}$ Department of Marine Science, University of Calcutta, India \\ ${ }^{5}$ Green Land Landscaping and Gardening, Seedling Growth Laboratory, Parana, Brazil
}

Ricardo Gobato ${ }^{1 *}$, Ibtihal Kadhim Kareem Dosh ${ }^{2}$, Alireza Heidari ${ }^{3}$, Abhijit Mitra ${ }^{4}$ and Marcia Regina Risso

*Corresponding author: Ricardo Gobato Laboratory of Biophysics and Molecular Modeling Genesis, State Secretariat of Education of Parana, Brazil.
Received Date: October 16, 2019

Published Date: October 31, 2019

Abbreviations: SAXS: Small-Angle X-Ray Scattering; USAXS: Ultra-Small Angle X-Ray Scattering; FXS: Fluctuation X-Ray Scattering; WAXS: Wide-Angle X-Ray Scattering; GISAXS: Grazing-Incidence Small-Angle X-Ray Scattering; GIWAXS: Grazing-Incidence Wide-Angle X-Ray Scattering; SANS: Small-Angle Neutron Scattering; GISANS: Grazing-Incidence Small-Angle Neutron Scattering XRD: X-Ray Diffraction Powder; PXRD : X-Ray Diffraction; WAXD: Wide-Angle X-Ray Diffraction; GIXD: Grazing- Incidence X-Ray; EDXRD: Diffraction; Energy-Dispersive X-Ray Diffraction

\section{Mini Review}

The rhodochrosite as crystal oscillator for being an alternative to those of quartz. The rhodochrosite (MnC03) shows complete solid solution with siderite (FeCO3), and it may contain substantial amounts of $\mathrm{Zn}, \mathrm{Mg}$, Co, and $\mathrm{Ca}$. There is no precedent in the literature on the treatment of tumor tissues by eliminating these affected tissues, using rhodocrosite crystals in tissue absorption and eliminating cancerous tissues by synchrotron radiation.

Through an unrestricted Hartree-Fock (UHF) computational simulation, Compact effective potentials (CEP), the infrared spectrum of the protonated rhodochrosite crystal, CH19Mn608, and the load distribution by the unit molecule by two widely used methods, Atomic Polar Tensor (APT) and Mulliken, were studied. The rhodochrosite crystal unit cell of structure CMn608, where the load distribution by the molecule was verified in the UHF CEP4G (Effective core potential (ECP) minimal basis), UHF CEP-31G (ECP split valance) and UHF CEP-121G (ECP triple-split basis).
The largest load variation in the APT and Mulliken methods were obtained in the CEP-121G basis set, with $\delta=2.922$ e $\delta=2.650$ u.a., respectively, being $\delta A P T>\delta$ Mulliken. The maximum absorbance peaks in the CEP-4G, CEP-31G and CEP-121G basis set are present at the frequencies $2172.23 \mathrm{~cm}^{-1}$, with a normalized intensity of $0.65 ; 2231.4 \mathrm{~cm}^{-1}$ and 0.454 ; and $2177.24 \mathrm{~cm}^{-1}$ and 1.0 , respectively (Figure 1).

The rhodochrosite unit cell was protonated, then presented the structure CH19Mn608 for the study with ab initio methods with +4 multiplicity. The displacement of charges by the molecule was analyzed to verify the site of molecular action (Table 1).

The Mulliken load method in the UHF-CEP-4G base set; UHFCEP-31G and UHF-CEP-121G are sufficient to show that the sites of action of the rhodochrosite crystal structure are found in three Oxygen-linked Manganese atoms, which are attached to the central Carbon atom, as well as these. Oxygen atoms and the central Carbon. 
These Manganese atoms show a slight negative to neutral load shift in the CEP-4G set basis, neutral to positive in the CEP-31G and CEP-121G set basis at the Mulliken loads. The charge displacement is strong in the oxygen atoms, especially those near the central carbon, with negative load in all set basis studied, both in the APT and Mulliken loads.

Table 1: Peaks maximum absorption intensity by the frequency given. Absorbance frequency as a function of vibrational frequencies of protonated rhodochrosite crystal for UHF-CEP-4G basis set, UHF-CEP-31G and UHF-CEP-121G.

\begin{tabular}{|c|c|c|c|c|c|c|c|c|}
\hline & $v\left(\mathrm{~cm}^{-1}\right)$ & $\mathrm{I}(\%)$ & $v\left(\mathrm{~cm}^{-1}\right)$ & $\mathrm{I}(\%)$ & $v\left(\mathrm{~cm}^{-1}\right)$ & $\mathrm{I}(\%)$ & $v\left(\mathrm{~cm}^{-1}\right)$ & $\mathrm{I}(\%)$ \\
\hline CEP-4G & 2172.23 & 64.9904 & 2043.25 & 51.7671 & 2193.1 & 41.6608 & 2242.97 & 36.4643 \\
\hline CEP-31G & 2231.4 & 45.3589 & 1891.26 & 41.6207 & 2027.77 & 40.3978 & 1926.32 & 38.0064 \\
\hline CEP-121G & 2177.24 & 100 & 2261.98 & 87.0553 & 1947.03 & 83.1151 & 1778.57 & 51.6624 \\
\hline
\end{tabular}

$\mathrm{v}=$ Frequency $\left(\mathrm{cm}^{-1}\right) ; \mathrm{I}=$ Normalized Intensity $(\%)$.

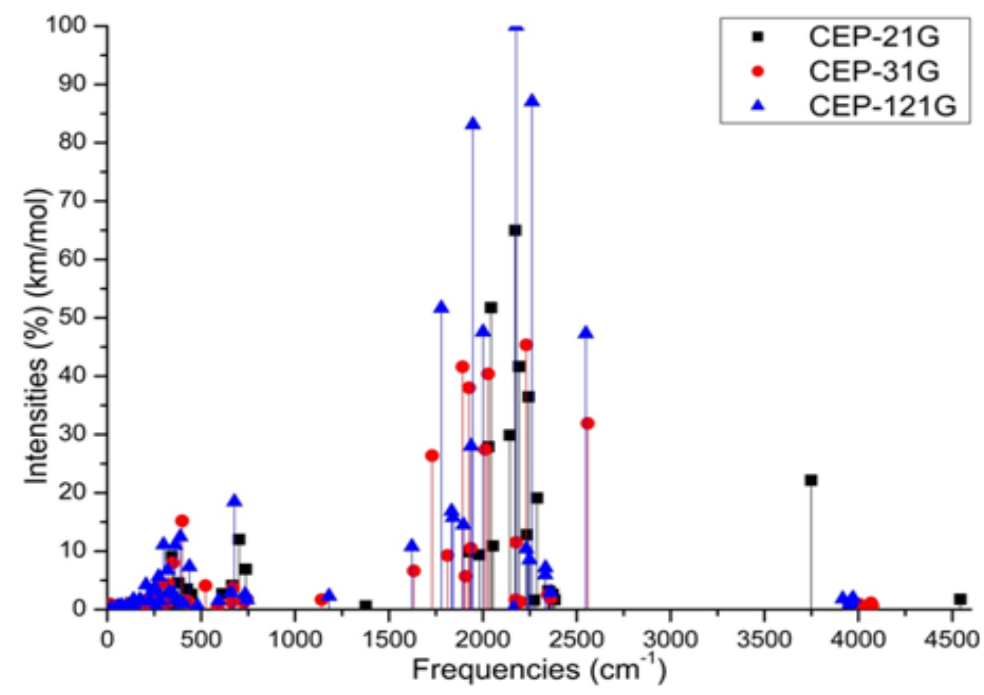

Figure 1: Absorbance spectrum plot as a function of vibrational frequencies of protonated rhodochrosite crystal for UHF-CEP-4G basis set, UHF-CEP-31G and UHF-CEP-121G.

The central carbon atom on all set basis is positively charged in both APT and Mulliken load, except Milliken in CEP-31G, which is neutral. As might be expected from the charges by APT, the strong positive load manganese atoms, the strong negative load oxygen, the positively charged carbon atom. The manganese atom farthest from the carbon atom has a slight positive to neutral load shift. The Mulliken load method presents a better result when compared to the APT, in the studied set basis, for protonated rhodochrosite crystal, with a smaller load variation $\delta=2,650$ u.a for CEP-121G. The absorption peaks are in a Gaussian between the frequencies $1620 \mathrm{~cm}^{-1}$ and $2520 \mathrm{~cm}^{-1}$.

The infrared rhodochrosite spectrum of the vibration absorbance frequencies was obtained to verify that these frequencies should be used in synchrotron radiation, which can destroy cancerous cells by absorbing such crystals. Hartree-Fock methods also analyzed APT and Mulliken charges, verifying the main binding sites of Manganese, Oxygen and Carbon atoms in cancerous tumors. Later studies could check the advantages and disadvantages of rhodochrosite in the treatment of cancer through synchrotron radiation, such as one oscillator crystal. An in-depth study is necessary to verify the absorption by the tumoral and non-tumoral tissues of rhodochrosite, before and after irradiating of synchrotron radiation using Small-Angle X-Ray Scattering (SAXS), Ultra-Small Angle X-Ray Scattering (USAXS), Fluctuation X-Ray Scattering (FXS), Wide-Angle X-Ray Scattering (WAXS), Grazing-Incidence Small-Angle X-Ray Scattering (GISAXS), Grazing-Incidence Wide-Angle X-Ray Scattering (GIWAXS), Small-Angle Neutron Scattering (SANS), Grazing-Incidence SmallAngle Neutron Scattering (GISANS), X-Ray Diffraction (XRD), Powder X-Ray Diffraction (PXRD), Wide-Angle X-Ray Diffraction (WAXD), Grazing- Incidence X-Ray Diffraction (GIXD) and EnergyDispersive X-Ray Diffraction (EDXRD).

\section{Acknowledgement}

None.

\section{Conflicts of Interest}

No conflicts of interest. 